\section{Dentin Sealing and Bond Strength Evaluation of Hema-Free and Multi- Mode Adhesives to Biomodified Dentin}

Renata Bacelar-Sá1, Marcelo Giannini', Glaucia Maria Bovi Ambrosano², Ana Karina Bedran-Russo ${ }^{3}$

\author{
'Department of Restorative \\ Dentistry, Dental Materials \\ Division, Piracicaba Dental School, \\ UNICAMP - Universidade Estadual \\ de Campinas, Piracicaba, SP, Brazil \\ ${ }^{2}$ Department of Social Dentistry, \\ Biostatistics Division, Piracicaba \\ Dental School, UNICAMP - \\ State University of Campinas, \\ Piracicaba, SP, Brazil \\ ${ }^{3}$ Department of Restorative Dentistry, \\ College of Dentistry, University of \\ Illinois at Chicago, Chicago, IL, USA
}

Correspondence: Dr. Marcelo Giannini, Avenida Limeira, 901 13414-903 Piracicaba, SP, Brasil. Tel:+55-19-2106-5340. e-mail: giannini@fop.unicamp.br

Key Words: dentin, bond strength, adhesives, cross-linking agent.

\section{Introduction}

The simplifications of adhesive systems and reduced numbers of steps for application have produced materials with high concentration of hydrophilic monomers. Consequently, such changes in the composition of adhesives led to lower effectiveness over time. The increase of the concentration of hydrophilic monomers such as HEMA, and the lack of a hydrophobic or bonding resin produce a semipermeable adhesive layer, which does not seal the dentin properly $(1,2)$.

Some manufacturers have reduced the hydrophilicity and added less hydrophilic monomers of some adhesives in attempt to increase the bonding longevity $(3,4)$. HEMA monomer ensures good dentin wetting and improves the stability of adhesive solutions containing hydrophobic and hydrophilic monomers. However, studies have shown that restorations bonded with HEMA-containing adhesives are more susceptible to water absorption and consequent hydrolytic degradation $(2,5,6)$. Besides eliminating the HEMA, the incorporation of fillers, fluorides and functional monomers also seem to contribute to increased longevity of the resin composite restorations $(2,7)$.

A different approach to provide longer durability of adhesive restorations is dentin biomodification, which consist of dentin treatment with collagen cross-linkers agents. Studies have shown that these agents improve collagen mechanical properties and reduce their sensitivity to denaturation and degradation $(8,9)$. Two examples of collagen cross-linkers agents are the glutaraldehyde and proanthocyanidin solutions, which have been able to improve dentin collagen stability and bond strength of conventional etch-and-rinse adhesives to dentin $(10,11)$.

The objectives of this study were to evaluate the influence of collagen cross-linking agents on the dentin bond strength of HEMA-free and multi-modes (HEMAcontaining) adhesives and the dentin sealing after $24 \mathrm{~h}$ and 6 months of water storage. The null hypotheses tested were: (1) bond strength of HEMA-free to biomodified dentin would not differ from multi-mode adhesives and (2) collagen cross-linking agent would not affect the dentin sealing.

\section{Material and Methods Microtensile Bond Strength}

Sixty sound third molars were stored in thymolsaturated solution at $4{ }^{\circ} \mathrm{C}$ and used within 3 months following extraction (Ethics Committee Approval \# 056/2015). The occlusal surface of the teeth was abraded with 180 and 320 grit silicon carbide (SiC) papers (Buehler, 
Lake Bluff, IL, USA) under cooling water to expose a flat dentin surface. Two groups of adhesives were selected for this study: HEMA-free and HEMA-containing/multi-mode adhesives. The HEMA-free systems were: a single-step selfetch (G-Aenial, GC Corp., Tokyo, Japan) and a three-step etch-and-rinse All-Bond 3 (Bisco Inc., Schaumburg, IL, USA), while the HEMA-containing/multi-mode adhesives were: Scotchbond Universal (3M ESPE, St. Paul, MN, USA) used in self-etch mode and Prime \& Bond Elect (Dentsply Caulk, Milford, DE, USA) used as two-step etch-and-rinse. The composition, lot number and application mode for each adhesive are depicted in Table 1.

Before bonding procedures, the dentin surfaces were polished with $600 \mathrm{SiC}$ paper (Buehler) for 10 s under cooling water and air-dried $(n=5)$. All adhesives were used according to the manufacturers' instructions and applied to dentin following three treatments: untreated dentin (control), 5\% glutaraldehyde (Sigma-Aldrich, St. Louis, MO, USA) and 6.5\% proanthocyanidin-rich grape seed extract (Madera, CA, USA). Glutaraldehyde and proanthocyanidin-rich grape seed extract were dissolved in deionized water and the $\mathrm{pH}$ was adjusted to 7.2 using $\mathrm{NaOH}$ at room temperature. Both solutions were applied for $10 \mathrm{~min}$ and washed for $3 \mathrm{~min}$ $\Xi$ prior to adhesives application (11).

For self-etch adhesives, the cross-linking agents were applied before bonding, while for etch-and-rinse adhesives the cross-linking agents were applied after phosphoric acid etching. After bonding, a $6 \mathrm{~mm}$-high composite block was incrementally built-up using resin composite
(Filtek Supreme Ultra, A2, body shade; 3M ESPE, St. Paul, MN, USA). Each increment had $2 \mathrm{~mm}$ thickness and was light-cured for $20 \mathrm{~s}$ using the halogen unit (Optilux 501; Kerr Corp., Orange, CA, USA).

The teeth were kept in distilled water at $37{ }^{\circ} \mathrm{C}$ and for $24 \mathrm{~h}$. Afterwards teeth were sectioned perpendicular to the interface using a low-speed diamond saw (Buehler) in order to produce dentin-resin beams with $1 \mathrm{~mm} 2$ at cross-sectional area. Eight to 12 beams were obtained per tooth and half of beams were tested in tension (Micro Tensile Tester; Bisco) after sectioning, while the other half was stored in distilled water for 6 months and then tested using the microtensile device. The water was changed every 4 weeks when beams were stored for 6 months. Beams were fixed to a microtensile device with cyanoacrylate glue (Super Bonder, Loctite; Henkel Corp., Rocky Hill, CT, USA) and tested at a crosshead speed of $1 \mathrm{~mm} / \mathrm{min}$ until fracture. The failed interface cross-sectional area of each sample was measured with a digital caliper, and the value (in $\mathrm{mm} 2$ ) was divided by the peak tensile load at failure to calculate stress at fracture (in MPa). A single failure stress value was calculated for each tooth (statistical unit) by averaging the values of beams from that tooth (four to six beams from the same tooth for each evaluation time). Data were analyzed by Proc Mixed and multiple comparisons using Tukey-Kramer test $(\alpha=0.05)$.

All fractured beams were analyzed according to the failure mode, using a scanning electron microscope (JSM5600, JEOL Inc., Peabody, MA, USA). Beams were air-dried

Table 1. Compositions, lot numbers and manufacturer's instructions of the tested adhesive systems

\begin{tabular}{|c|c|c|c|}
\hline Adhesive & Batch \# & Composition & Manufacturer's instructions \\
\hline $\begin{array}{l}\text { Scotchbond } \\
\text { Universal }\end{array}$ & 527600 & $\begin{array}{l}\text { HEMA, MDP, Filler, Dimethacrylate resins, Vitrebond } \\
\text { Copolymer, Ethanol, Water, Initiators, Silane. }\end{array}$ & $\begin{array}{l}\text { 1- Scrub adhesive for } 20 \mathrm{~s} \text { on dentin; } \\
\text { 2- Gently air thin for } 5 \mathrm{~s} \text {; } \\
\text { 3- Light cure for } 10 \mathrm{~s} \text {. }\end{array}$ \\
\hline $\begin{array}{l}\text { Prime \&t } \\
\text { Bond Elect }\end{array}$ & 130811 & $\begin{array}{l}\text { HEMA, 2-hydroxy-3-acryloyloxypropyl methacrylate, } \\
\text { Urethane dimethacrylate, Trimethylolpropane trimethacrylate, } \\
\text { PENTA, Diketone, Organic phosphine oxide, Stabilizers, } \\
\text { Cetylamine hydrofluoride, Acetone, Water. }\end{array}$ & $\begin{array}{l}\text { 1- Etch for } 15 \mathrm{~s} \text { and rinse for } 15 \mathrm{~s} \text {; } \\
\text { 2- Apply the adhesive agitating for } 20 \mathrm{~s} \text {; } \\
\text { 3- Gently air dry for } 5 \mathrm{~s} \text {; } \\
\text { 4- Light cure for } 10 \mathrm{~s} \text {. }\end{array}$ \\
\hline All-Bond 3 & $\begin{array}{c}\text { Part. A } \\
1300005995 \\
\text { Part. B } \\
1300005996\end{array}$ & $\begin{array}{l}\text { N(p-tolyl)glycine and glycidyl methacrylate } \\
\text { and Ethanol (Part. A), } \\
\text { Bis-GMA (Part. B). }\end{array}$ & $\begin{array}{l}\text { 1- Etch for } 15 \mathrm{~s} \text { and rinse for } 15 \mathrm{~s} \text {; } \\
\text { 2- Mix an equal number of drops } \\
\text { of Parts A and B for } 5 \mathrm{~s} \text {; } \\
\text { 3- Apply 1-2 coats with light } \\
\text { agitating for } 5-10 \mathrm{~s} \text {; } \\
\text { 4- Gently air for } 5 \mathrm{~s} \text {, then dry } \\
\text { thoroughly for } 10 \mathrm{~s} \text {; } \\
\text { 5- Light cure for } 10 \mathrm{~s} \text {. }\end{array}$ \\
\hline G-Aenial & 1306181 & $\begin{array}{l}\text { Dimethacrylate, 4-META, Phosphoric Acid Ester Monomer, } \\
\text { Silicon dioxide, Photoinitiator, Acetone, Water. }\end{array}$ & $\begin{array}{l}\text { 1- Apply the adhesive; } \\
\text { 2- Waiting for } 10 \mathrm{~s} \text {; } \\
\text { 3- Strongly air dry for } 5 \mathrm{~s} \text {; } \\
\text { 4- Light cure for } 10 \mathrm{~s} \text {. }\end{array}$ \\
\hline
\end{tabular}

Compositions according to the MDSD provide by respective manufacturers: Hydroxyethylmethacrylate (HEMA); Methacryloyloxydecyl dihydrogen phosphate (MDP); Dipentaerythritol penta acrylate monophosphate (PENTA); Bisphenol-glycidyl methacrylate (Bis-GMA); 4-Methacryloxyethyltrimellitate anhydride (4-META). 
overnight at $37{ }^{\circ} \mathrm{C}$, sputter-coated with gold (MED 010, Bal-Tec, Balzers, Liechtenstein) and fractured surfaces were classified as follows: (1) adhesive along the dentin surface (ADS), (2) cohesive within the dentin (CWD) and (3) cohesive within the resin composite, and between adhesive and resin composite (CRC).

\section{Dentin Sealing}

In this part of the study, forty sound third molars (Ethics Committee Approval \# 056/2015) of similar size were used to measure the fluid filtration $(\mu \mathrm{L} / \mathrm{min})$. Teeth were prepared similarly as described for bond strength test to obtain flat dentin surfaces. For all teeth, the remaining dentin thickness was between 1.0 and $1.5 \mathrm{~mm}$ (considering the flat occlusal dentin surface the pulp horns), which was measured with a digital caliper (Golgran, São Paulo, SP, Brazil). The roots were removed $1 \mathrm{~mm}$ below the cementum-enamel junction and the pulp tissue was removed carefully with a \#40 Hedstrom file (Maillefer/Dentsply; Johnson City, TN, USA).

Each tooth was fixed on an acrylic plate $(30 \mathrm{~mm}$ wide $X$ $30 \mathrm{~mm}$ length $X 5 \mathrm{~mm}$ thickness) using a cyanoacrylate glue (Super Bonder, Loctite, Henkel). The plate was perforated in the center and an 18 gauge stainless steel tube was fixed in that hole to allow the pulp chamber to be completely filled with water. The set crown and plate were plugged into a hydraulic pressure device, which was connected to a water reservoir positioned $140 \mathrm{~cm}$ above the dentin surface, creating a pressure of $2 \mathrm{psi}$ or $10.29 \mathrm{~cm} \mathrm{Hg}$, as described by Rusin et al. (12). The hydraulic pressure device used in this study was similar to that designed by Carvalho et al. (13).

The minimum fluid filtration (MIFF) was measured as a parameter for specimen comparison after treatments and storage. MIFF was measured after the dentin was abraded with $600 \mathrm{SiC}$ paper (Buehler) for 10 under cooling water and air-dried. Afterward, the dentin surfaces of the teeth were treated with $0.5 \mathrm{M}$ EDTA (pH 7.4) for 5 min, washed with water for $1 \mathrm{~min}$, ultrasonically cleaned (Ultrasonic Cleaner, Kendal Industrial Grade, Singapore) in distilled water for $12 \mathrm{~min}$ and the maximum fluid filtration (MAFF) was measured, which was defined as $100 \%$ permeability for each tooth.

The teeth used in this part of the study presented MAFF values, which ranged from 0.5 to $2.0 \mathrm{~mm}$ $\mu \mathrm{L} / \mathrm{min}$. Then, teeth were divided into sub-groups (1- 0.5 to $1.2 \mu \mathrm{L}$ ) $\min$ and $2-1.3$ to $2.0 \mu \mathrm{L} / \mathrm{min})$ to ensure that each group had the same amount of teeth with similar dentin permeability and fluid filtration rate. The forty teeth were divided into 8 experimental groups $(n=5)$, according to the four adhesives tested and application of cross-linkers or not. The dentin sealing was studied only for proanthocyanidin-rich grape seed extract, because it was the collagen cross-linker agent that most influenced the bond strength (Table 2).

After MAFF measurement, new smear layer was recreated on the dentin surface using $600 \mathrm{SiC}$ paper under cooling water for $10 \mathrm{~s}$. The $6.5 \%$ proanthocyanidin-rich grape seed extract was applied for 10 min or not (control group) and hydraulic conductance was measured again (FFTD). The group with cross-linking application had 5 measurements: MIFF, MAFF, FFTD (fluid flow through cross-linking-treated dentin), FFHD (fluid flow through hybridized dentin) and after 6 months (FF6M).

After adhesive application the fourth measurement was performed (FFHD). During the bonding procedures, the specimens still remained attached to the permeability device, but without pulpal pressure, simulating the condition of a patient under anesthesia. Afterwards, the teeth were stored in distilled water, keeping the adhesive directly exposed to the water for 6 months and then the last measurement was performed (FF6M). The values for all the measurements for adhesives were compared. MIFF and MAFF of each tooth served as their own control. The percentages of reduction of fluid flow through the crosslinking treated-dentin (FFTD), after adhesive application on dentin (FFHD) and after 6 months (FF6M) were calculated. The equation below was used to calculate the percentage of dentin sealing provided by application of the cross-linkers,
Table 2. Mean (SD) microtensile bond strength (MPa) of treatment, adhesive systems and time to dentin.

\begin{tabular}{|c|c|c|c|c|}
\hline \multirow{2}{*}{$\begin{array}{l}\text { Evaluation } \\
\text { Time }\end{array}$} & \multirow{2}{*}{ Adhesive } & \multicolumn{3}{|c|}{ Treatment } \\
\hline & & Control & Glutaraldehyde & Proanthocyanidin \\
\hline \multirow{4}{*}{$24 \mathrm{~h}$} & Scotchbond Universal & $55.2(5.5) \mathrm{B} \mathrm{a}$ & 56.9 (6.8) $\mathrm{AB}$ a & 64.7 (9.1) A a \\
\hline & Prime \& Bond Elect & $51.9(6.3) \mathrm{B}$ a & $57.2(10.5) \mathrm{AB}$ a & $63.0(13.4) \mathrm{A} \mathrm{a}$ \\
\hline & All-Bond 3 & 48.1 (10.2) B a & $61.1(8.0) \mathrm{AB}$ a & 63.8 (4.4) A a \\
\hline & G-Aenial & 12.2 (7.0) B b & 15.5 (8.4) AB b & 20.7 (8.8) A b \\
\hline \multirow{4}{*}{6 months } & Scotchbond Universal & 50.6 (6.8) A a & ${ }^{*} 43.0$ (7.9) A a & *48.9 (7.4) A ab \\
\hline & Prime \& Bond Elect & 49.6 (5.8) A a & $51.8(4.4) \mathrm{A} \mathrm{a}$ & 57.7 (8.2) A a \\
\hline & All-Bond 3 & $45.8(12.6) \mathrm{A} \mathrm{a}$ & ${ }^{*} 46.1$ (6.8) A a & *39.3 (5.9) A b \\
\hline & G-Aenial & $13.7(5.0) \mathrm{A} \mathrm{b}$ & 13.5 (5.5) A b & $18.1(11.4) \mathrm{A} \mathrm{C}$ \\
\hline
\end{tabular}

Groups having similar letters (upper cases: compare treatments within the same adhesive; lower cases: compare adhesives within the same treatment and evaluation time) are not significantly different. *Differ from 24 hours at the same condition of treatment and adhesive $(p<0.05)$. 
adhesives and 6-months:

Dentin sealing $(\%)=100 \times($ MIFF - FFTD or FFHD or FF6M) / MAFF

\section{Results}

The statistical analysis demonstrated that the type of adhesive, treatment and evaluation time significantly influenced the bond strength results. Dentin bond strength means and standard deviations are shown in Table 2. G-Aenial showed the lowest bond strength results regardless of treatment and evaluation time. Scotchbond Universal, Prime \& Bond Elect and All-Bond 3 did not differ among them regardless of dentin treatment and evaluation time, except at 6 months because the application of Prime \& Bond Elect on 6.5\% proanthocyanidin extract-treated dentin, which yielded higher bond strength than that for All-Bond 3.

The use of 5\% glutaraldehyde solution did not increase the dentin bond strength of no adhesive when compared to control (untreated-dentin); however, the results did not differ from $6.5 \%$ proanthocyanidin extract, which increased the bond strength of all adhesives when compared to the control group only at $24 \mathrm{~h}$.

The bond strength of Prime \& $\mathrm{B}$ Bond Elect and G-Aenial did not reduce after six months of water-storage, regardless of the dentin treatment. However, the bond strength of Scotchbond Universal and All-Bond 3 to cross-linking agentx treated-dentin (with glutaraldehyde and proanthocyanidin extract) decreased after six months. When Prime \& Bond Elect was applied to proanthocyanidin extract treated-dentin, higher bond strength was obtained than those for All-Bond 3 and G-Aenial adhesives at six months.

Scotchbond Universal (ADS: 45\%, CWD: 20\% and CRC: 35\%), Prime \&t Bond Elect (ADS: 40\%, CWD: 25\% and CRC: 35\%) and All-Bond 3 (ADS: 50\%, CWD: 30\% and CRC: 20\%) presented the three failures modes and the water-storage for 6 months did not alter their failures mode. The G-Aenial adhesive showed predominance of adhesive failures in both evaluation times (ADS: 95\% and CRC: $5 \%$ ).

Regarding dentin sealing, the $6.5 \%$ proanthocyanidin extract and/or adhesives (in control groups) were able to completely seal de dentin surface and values were not different from MIFF (with smear layer). The complete dentin sealing (100\%) remained after 6 months independently on the adhesive type.

\section{Discussion}

The first null hypothesis that bond strength of HEMAfree to biomodified dentin would not differ when compared to multi-mode adhesive was rejected, because G-Aenial HEMA-free adhesive showed lower bond strength than those found for Prime \&t Bond Elect and Scotchbond Universal (both the HEMA containing-adhesives). Moreover, Prime \& Bond Elect presented higher bond strength to biomodified dentin than All-Bond 3 at 6 -months. In this study, different strategies of adhesion, etch-and-rinse and self-etch approaches were used. For etch-andrinse approach, the phosphoric acid etching completely removes the smear layer and demineralizes the dentin surface, affecting the its morphology and physiology. The morphological change occurs due to the mineral removal, which exposes collagen fibrils. As consequence of the mineral removal, in deep cavity preparation, the dentin permeability increases because of the water diffusion from dentin tubules (14), impairing the adhesive monomers infiltration and its polymerization reaction; thus creating a permeable hybrid and adhesive layer $(1,2)$. Acid etching demineralizes and poorly infiltrated dentin by adhesive monomers can induce collagen degradation by matrix metalloproteinases and cysteine cathepsins $(9,15)$, while the hydrolytic degradation of adhesive polymers and oligomers can occur by water diffusion that increases the nanoleakage along the interface $(5,6)$.

With the focus on reducing time and steps for adhesive application, manufacturers developed one-step self-etching adhesives, which contain hydrophilic and hydrophobic components in a single solution. These adhesives need to be able to diffuse beyond the smear layer and smear plugs to bond with intertubular dentin and form resin tags inside the tubules, respectively. The most prevalent adhesion happens in the intertubular dentin by the diffusion of adhesive monomers, which is called hybridization and represents the primary mechanism to obtain the micro-mechanical retention and sealing (2). The self-etch single-step adhesives form a very thin hybrid layer, which traditionally tends to form a semi-permeable layer that does not seal completely the dentin (1). However, another study demonstrated that different bonding approaches could prevent the movement of water across the dentin (16), but it must be considered that different self-etching adhesives were used in that study, which present different monomer composition, water content and acidity level (2).

Adhesives that contain hydrophilic monomer such as HEMA tend to absorb more water than hydrophobic resins, accelerating the polymeric hydrolytic degradation at the bonded interface $(2,6)$. In addition, HEMA monomer is cytotoxic and when using etch-and-rinse approach in deep cavities, it is able diffuse through the dentin and resulting in hypersensitivity reaction and pulp inflammation (17). Based on these disadvantages, HEMA-free adhesives, which in theory absorb less water over time, may result in increasing of bonding longevity $(3-6,18)$.

Two adhesives tested in this study showed bond strength 
reduction after 6-months of water storage when applied to cross-linking treated dentin. One of them was the HEMAcontaining/multi-mode adhesive (Scotchbond Universal) and the other was the All-Bond 3, which is HEMA-free. Conversely, no change in the bond strength was noted when applied to untreated dentin. Scotchbond Universal contains 10-MDP monomer, which presents chemical interaction with hydroxyapatite, yielding long-term of bonding stability against biodegradation $(2,7)$. However, this adhesive was applied in self-etch mode and this chemical interaction with hydroxyapatite may not occur strongly in biomodified dentin. Scotchbond Universal also has vitrebond copolymer that is able to create an extra ionic bond to hydroxyapatite, which tends reduce microleakage by enhancing the dentin sealing ability (19). However, vitrebond copolymer is a polyalkenoic acid copolymer that has high affinity to water and may cause phase separation within the adhesive layer and hybrid layer. Moreover, polyalkenoic acid copolymer has a high molecular weight and keeps predominantly trapped on the dentin surface $(2,20)$. Additionally, HEMA is a hydrophilic monomer that may uptake water, jeopardizing the integrity of hybrid layer over time $(2,5,6)$.

The absence of HEMA can cause phase separation, in which adhesive monomers separate from water upon evaporation of ethanol or acetone organic solvents contained in primers and adhesive solutions. Droplets entrapped within the adhesive applied to dentin impair the polymerization, reducing the bond durability. To overcome the phase separation, strong air-drying is recommended to remove the interfacial water (21). Part A of All-Bond 3 is ethanol-based formula; however, Part $B$ is a hydrophobic radiopaque filled bonding resin without HEMA. Although multi-step adhesives, such as All-Bond 3 , are more effective to enamel/dentin than single-step adhesives, the bond strength of the three-steps etch-and-rinse adhesive reduced after six months when applied to cross-linking treated dentin, showing that the interaction of this adhesive with treated collagen was not stable over time.

As the monomer-solvent phase separation can also occur in single-step self-etching adhesives, the manufacturer of G-Aenial recommends a strong spray of oil-free air to completely evaporate the water content. The lowest bond strength found for this adhesive in this study may be related in parts to not enough air-drying and solvent evaporation (22). However, the water-storage for six months did not affect the bond strength, because the 4-META functional monomer is able to establish an ionic bond with calcium in hydroxyapatite, but less intense than other functional monomers, such as 10-MDP (2). The predominance of adhesive failure observed in the analysis of fracture pattern may be related to lower bond strength for G-Aenial. Conversely, some in vivo studies showed that the performance of G-Bond (first version of G-Aenial) is considered clinically acceptable $(3,4)$ and an in vitro study demonstrated that the water sorption and ultimate tensile strength of that adhesive did not change after 360-day water storage, which did not occur for HEMA-containing adhesives (18).

In this study, Prime \&t Bond Elect multi-mode adhesive was used in etch-and-rinse mode and was not affected by water storage for one year. Its main functional monomer is PENTA and also it contains more three methacrylate monomers in an acetone solution. There are few investigations that evaluated performance of Prime \& $\mathrm{Bond}$ Elect $(23,24)$; however, in this study it presented adequate results when compared to other adhesives, which indicates good perspective for bonding durability even with HEMA in its composition.

The second null hypothesis was also rejected, because the proanthocyanidin-rich grape seed extract strongly influenced the dentin sealing. A previous study that evaluated the effect of cross-linking agents (glutaraldehyde and proanthocyanidin extract) on dentin bond strength showed improvement of immediate adhesion, but the stabilization of bonding after long-term storage depended on the adhesive type (11). Dentin biomodification is a biomimetic strategy therapy to enhance the collagen scaffold biomechanically and reduce biodegradability against endogenous and exogenous proteases (9). However, the application time used in this study is not clinically feasible, since it spends 10 minutes and plus 3 minutes for washing prior bonding. A recent study found that lower application time of proanthocyanidin can also provide effective cross-linking of collagen, improving its biostability in time periods as short as 1 minute and the durability of current dentin bonding agents (25).

Glutaraldehyde is a synthetic aldehyde collagen cross-linking agent that decreases the rate of collagen degradation (26). However, it presents high cytotoxicity (8), which limited their clinical use. Proanthocyanidin from grape seed extract is a natural safe compound and works as well as glutaraldehyde (27). Proanthocyanidin extract stabilizes and increases the density of type-I collagen network (26), which improves the dentin mechanical properties and decreases the swelling ratio that may indicate a matrix resistance against enzymatic degradation $(11,26)$. The results of the present study did not show a statistically difference between glutaraldehyde and proanthocyanidin extract at $24 \mathrm{~h}$ for all adhesives studied. However, proanthocyanidin seems to have more ability to interact with collagen and increase the mechanical properties of dentin when compared to glutaraldehyde (10). Because of the bond strength values found in this 
study, it was selected for the permeability test.

To evaluate the ability of adhesive systems of sealing the dentin, the permeability test was performed to simulate pulpal pressure of $140 \mathrm{~cm}(2$ psi or $10.29 \mathrm{~cm} \mathrm{Hg}$ ) using water column as described by Rusin et al. (12), which tried to simulate in vivo conditions. Previous studies used ten psi, which is five times more than used in this study. In those studies, no adhesive tested completely sealed bovine dentin, but self-etching systems showed better sealing ability than three-step etch-and-rinse adhesive, indicating that the wet bonding technique seemed to be more sensitive for dentin sealing in that conditions $(3,4,21)$. This study used two psi and the outcomes indicated that all adhesives were able to seal the dentin as smear layer did even after 6 months exposed to water.

The initial assessment of dentin sealing (minimum fluid filtration) was carried out in the presence of smear layer that was considered the lowest permeability, as the smear layer seals the dentin tubules by smear plugs formation from small debris of tooth structures during the abrasion with abrasive papers (14). The dentin biomodification promoted by proanthocyanidin extract from grape seeds and the adhesives sealed dentin under two-psi pressure after smear layer removal by EDTA. This dentin sealing remained stable until 6 months, which is clinically important because the movement of water through the dentin-resin interface can leach unreacted monomers and small oligomers increasing the porosities and hydrolytic degradation of adhesive polymer. Considering that dentin-resin interface degradation depends on the stability of both structures involved in the bonding mechanism (dentin and adhesive monomers), the quality of biomodification of dentin and the high monomeric conversion of adhesives are important to keep bond strength stable over time.

The proanthocyanidin extract increased the dentin bond strength for all adhesives at 24 hours regarding controls, while no changes were observed with $5 \%$ glutaraldehyde treatment. However, the bond strength of a multi-mode (Scotchbond Universal) and a HEMA-free adhesive (AllBond 3) to dentin treated with proanthocyanidin extract decreased after water-storage for 6 months, but did not differ from their respective controls. Conversely, the other multi-mode adhesive (Prime \& Bond Elect) and the G-Aenial HEMA-free adhesive applied to treated-dentin showed stable bond strength, which also not differ from controls. The proanthocyanidin extract and/or adhesive application were able to completely seal the dentin at bonded interface, which kept sealed until 6 months. Although no difference was observed regarding dentin sealing, the type of adhesives (HEMA-free or multi-mode) influenced the bond strength results.

\section{Resumo}

Este estudo avaliou o efeito da biomodificação da dentina na resistência de união (BS) e capacidade de selamento (SA) de adesivos "HEMA-free" e "multi-mode" após 24 horas e 6 meses de armazenamento em água. Quatro adesivos foram testados: dois "multi-mode" (Scotchbond Universal - SU, e Prime \& Bond Elect - PB) e dois "HEMA-free" (All-Bond 3 - AB, e $\mathrm{G}$-Aenial - GA). Terceiros molares humanos foram selecionados e a dentina desses dentes foi tratada com dois agentes "cross-linking" (glutaraldeido $5 \%$ e extrato de uva contendo proantocianidina 6.5\% - PACs) por $10 \mathrm{~min}$ ou permaneceram sem tratamento (grupo controle) $(n=6)$. Os dentes foram seccionados e preparados para teste de BS e análise de SA. As mensurações de SA foram adquiridas com a presença de "smear layer" (mínima permeabilidade), tratamento com EDTA (máxima permeabilidade), aplicação dos PACs, aplicação de adesivo e após 6 meses de armazenamento em água. Os dados de BS foram analisados pelo Proc Mixed e teste de Tukey-Kramer $(\alpha=5 \%)$. A aplicação dos PACs aumentaram a BS para todos os adesivos testados no tempo de $24 \mathrm{~h}$. Entretanto, a BS reduziu para o adesivo SU e AB após 6 meses. Em geral, os adesivos "multi-mode" (SU e $\mathrm{PB}$ ) não diferiram do $\mathrm{AB}$ "HEMA-free". 0 adesivo $\mathrm{GA}$ apresentou o menor valor de $B S$ em ambos tempos de avaliação. A permeabilidade dentinária foi reduzida após a aplicação dos PACs e permaneceu a mesma até 6 meses, independente da aplicação do adesivo. Os PACs podem aumentar a BS independente do tipo de adesivo, entretanto somente para o adesivos PB e GA a BS manteve estável após 6 meses de armazenamento em água. Os PACs foram capazes de selar a dentina como a permeabilidade minima da dentina, que permaneceram estável após 6 meses.

\section{Acknowledgements}

The research was sponsored by FAPESP (grant \#2011/11415-1 and \#2013/13415-1) and NIH-NIDCR (grants \#R01DE021040). The authors thank the Writing Department (University General Coordinator) of UNICAMP, Brazil for the language services provided.

\section{References}

1. Tay FR, Pashley DH, Suh BI, Carvalho RM, Itthagarun A. Single-step adhesives are permeable membranes. J Dent 2002;30:371-382.

2. Van Landuyt KL, Snauwaert J, De Munck J, Peumans M, Yoshida $Y$, Poitevin A, et al.. Systematic review of the chemical composition of contemporary dental adhesives. Biomater 2007;28:3757-3785

3. Dijken JWV. A 6-year prospective evaluation of a one-step HEMA-free self-etching adhesive in Class II restorations. Dent Mater 2013;29:11161122.

4. Van Landuyt KL, De Munck J, Ermis RB, Peumans M. Five-year clinical performance of a HEMA-free one-step self-etch adhesive in noncarious cervical lesions. Clin Oral Investig 2014;18:1045-1052.

5. Jacobsen T, Soderholm KJ. Some effects of water on dentin bonding. Dent Mater 1995;11:132-136.

6. Yiu CK, King NM, Carrilho MR, Sauro S, Rueggeberg FA, Prati C, et al.. Effect of resin hydrophilicity and temperature on water sorption of dental adhesive resins. Biomater 2006;27:1695-1703.

7. Loguercio $A D$, de Paula EA, Hass V, Luque-Martinez I, Reis A, Perdigão J. A new universal simplified adhesive: $36-$ Month randomized doubleblind clinical trial. J Dent 2015;43:1083-1092.

8. Dos Santos PH, Karol S, Bedran-Russo AK. Long-term nano-mechanical properties of biomodified dentin-resin interface components. J Biomech 2011;44:1691-1694.

9. Bedran-Russo AK, Pauli GF, Chen SN, McAlpine J, Castellan CS, Phansalkar RS, et al. Dentin biomodification: strategies, renewable, resources and clinical applications. Dent Mater 2014;30:62-76.

10. Al-Ammar A, Drummond JL, Bedran-Russo AK. The use of collagen cross-linking agents to enhance dentin bond strength. J Biomed Mater Res B Appl Biomater 2009;91:419-424.

11. Castellan CS, Bedran-Russo AK, Antunes A, Pereira PNR. Effect of dentin biomodification using naturally derived collagen cross-linkers: One-year bond strength study. Int J Dent 2013;2013:918010. 
12. Rusin RP, Agee $K$, Suchko M, Pashley DH. Effect of a new desensitizing material on human dentin permeability. Dent Mater 2010;26:600-607.

13. Carvalho AO, Oliveira MT, Nikaido T, Tagami J, Giannini M. Effect of adhesive system and application strategy on reduction of dentin permeability. Braz Oral Res 2012;26:397-403

14. Mahdan MHA, Nakajima M, Foxton RM, Tagami J. Combined effect of smear layer characteristics and hydrostatic pulpal pressure on dentine bond strength of HEMA-free and HEMA-containing adhesives. J Dent 2013;41:861-871.

15. Tjäderhane L, Nascimento FD, Breschi L, Mazzoni A, Tersariol IL, Geraldeli $S$, et al.. Optimizing dentin bond durability: control of collagen degradation by matrix metalloproteinases and cysteine cathepsins. Dent Mater 2013;29:116-135.

16. Rosales-Leal Jl, de la Torre-Moreno FJ, Bravo M. Effect of pulp pressure on the micropermeability and sealing ability of etch \& rinse and selfetching adhesives. Oper Dent 2007;32:242-250.

17. Paranjpe $A$, Bordador LCF, Wang $M-Y$, Hume WR, Jewett $A$. Resin monomer 2-hydroxyethyl methacrylate (HEMA) is a potent inducer of a apoptotic cell death in human and mouse cells. J Dent Res 2005;84:172-177.

18. Takahashi M, Nakajima M, Hosaka K, Ikeda M, Foxton RM, Tagami J. Long-term evaluation of water sorption and ultimate tensile strength of HEMA-containing/-free one-step self-etch adhesives. J Dent 2011;39:506-512.

19. Mitra SB, Lee CY, Bui HT, Tantbirojn D, Rusin RP. Long-term adhesion and mechanism of bonding of a paste-liquid resin-modified glassionomer. Dent Mater 2009;25:459-466.
20. Tay FR, Gwinnett JA, Wei SHY. Micromorphological spectrum of acid-conditioned dentin following the application of a water-based adhesive. Dent Mater 1998;14:329-338.

21. Van Landuyt KL, De Munck J, Snauwaert J, Coutinho E, Poitevin A, Yoshida Y, et al.. Monomer-solvent phase separation in one-step selfetch adhesives. J Dent Res 2005;84:183-188.

22. Ikeda T, De Munck J, Shirai K, Hikita K, Inoue S, Sano H, et al.. Effect of air-drying and solvent evaporation on the strength of HEMA-rich versus HEMA-free one-step adhesives. Dent Mater 2008;24:1316-1323.

23. Chen C, Niu LN, Xie H, Zhang ZY, Zhou LQ, Jiao K, et al. Bonding of universal adhesives to dentine - Old wine in new bottles? J Dent 2015;43:525-536.

24. Takamizawa T, Barkmeier WW, Tsujimoto A, Endo H, Tsuchiya K, Erickson $\mathrm{RL}$, et al.. Influence of pre-etching times on fatigue strength of selfetch adhesives to enamel. J Adhes Dent 2016;18:501-511.

25. Leme-Kraus AA, Aydin B, Vidal CM, Phansalkar RM, Nam JW, McAlpine $J$, et al.. Biostability of the proanthocyanidins-dentin complex and adhesion studies. J Dent Res 2017;96:406-412.

26. Liu RR, Fang M, Zhang L, Tang CF, Dou Q, Chen JH. Anti-proteolytic capacity and bonding durability of proanthocyanidin-biomodified demineralized dentin matrix. Int J Oral Sci 2014;6:168-174.

27. Bedran-Russo AK, Pereira PN, Duarte WR, Drummond JL, Yamauchi M. Application of crosslinkers to dentin collagen enhances the ultimate tensile strength. J Biomed Mater Res 2007;80:268-272.

Received February 5, 2017 Accepted August 8, 2017 